\title{
Radiofrequency Denervation for Facet Syndrome: A Meta-Analysis of Treatment Outcomes
}

\section{Denervação de síndrome facetária por radiofrequência: metanálise de resultados de tratamentos}

\author{
Pedro Henrique Essado Maya ${ }^{1}$ Ledismar José da Silva ${ }^{2}$ Marina Dumont Palmerston ${ }^{1}$ \\ Antonio Márcio Teodoro Cordeiro Silva ${ }^{3}$ \\ ${ }^{1}$ Pontifícia Universidade Católica de Goiás (PUC-Goiás), Goiânia, GO, Brazil \\ 2 Functional Neurosurgeon, Professor at the Medical School, Pontifícia \\ Universidade Católica de Goiás (PUC-Goiás), Goiânia, GO, Brazil \\ Address for correspondence Ledismar José da Silva, MD, MSc, Rua \\ 1181, Qd 242-A, Lt 1/27, Casa 40, Setor Marista, 74180-100, Goiânia, \\ GO, Brazil (e-mail: ledismarsilva@gmail.com).
}

${ }^{3}$ Associate Professor at the Medical School, Pontifícia Universidade Católica de Goiás (PUC-Goiás), Goiânia, GO, Brazil

Arq Bras Neurocir 2016;35:111-117.

\begin{abstract}
Keywords

- radiofrequency

- facet joint

- lower back pain

\section{Resumo}

\section{Palavras-chave}

- radiofrequência

- articulação facetaria

- dor lombar

Objective The aim of this study was to carry out a systematic literature review on the facet syndrome and a meta-analysis of the outcomes of radiofrequency denervation in patients presenting with the syndrome.

Methods A systematic literature review was performed based on 52 articles published from 1999 to 2013, available at Bireme, Scielo, PubMed, and MEDLINE databases. The meta-analysis comprises eight case-control studies, found during the literature review, totaling 440 patients. The heterogeneity of the collected data was assessed using the chi-square test $\left(x^{2}\right)$. To estimate the effect of the proposed correlation, we combined the values of each study with the Mantel-Haensze test, which has fixed effects, using the BioEstat 5.0 software.

Results The selected studies were statistically relevant when grouped, determining an effect in favor of the use of facet denervation as a technique capable of relieving chronic low back pain in pre-determined periods of follow-up $(\mathrm{OR}=1.251 ; 95 \% \mathrm{Cl}$ : 1.028-1.524).

Conclusion The results of the systematic literature review and meta-analysis herein presented may be used for the creation of diagnosis and management protocols for facet syndrome, and can also attract the interest of other researchers to conduct further studies on the theme.

Objetivo Este estudo teve como objetivo elaborar uma revisão sistematizada sobre síndrome facetária e uma metanálise sobre os desfechos do tratamento neurocirúrgico com denervação por radiofrequência em pacientes acometidos por esta síndrome.

Métodos A revisão sistematizada foi elaborada com base em 52 artigos publicados de 2000 a 2013, disponíveis nas bases de dados eletrônicos Bireme, Scielo, PubMed e MEDLINE. A metanálise foi composta por oito casos-controle, selecionados durante a revisão, totalizando 440 pacientes. Os dados coletados foram avaliados quanto à sua
\end{abstract}

received

September 10, 2015 accepted

December 21, 2015

published online

March 2, 2016
DOI http://dx.doi.org/

10.1055/s-0036-1579554. ISSN 0103-5355.
Copyright $\odot 2016$ by Thieme Publicações License terms

Ltda, Rio de Janeiro, Brazil 
heterogeneidade pelo teste qui-quadrado $\left(x^{2}\right)$. Para estimar o efeito da correlação proposta, os valores de cada estudo foram combinados com o teste de MantelHaensze, que tem efeitos fixos, utilizando o software BioEstat 5.0.

Resultados Os estudos selecionados são estatisticamente relevantes quando agrupados, determinando um efeito a favor do uso da denervação facetária como técnica capaz de diminuir a lombalgia crônica em seguimentos pré-determinados, mostrando OR de 1,251 e IC95\% entre 1,028 e 1,524.

Conclusão Os resultados da revisão sistemática de literatura e da metanálise aqui apresentados podem servir de base para a criação de protocolos de diagnóstico e conduta da síndrome facetária, assim como despertar o interesse de outros pesquisadores para a condução de novos estudos sobre o tema.

\section{Introduction}

Facet syndrome is a cause of chronic low back pain with multifactorial etiology and generally occurs when the facet joint wears out or becomes degenerated. This can affect any structures that are a part of the facet joint such as fibrous capsule, synovial membrane, hyaline cartilage, joints, and adjacent structures known to contain thermal nociceptors. ${ }^{1-6}$

The term "facet syndrome" was coined in 1933 by Ghormley ${ }^{7}$ to describe the pain in the lumbosacral region, with or without sciatica, which can occur after an intense traumatic injury, such as a sudden neck rotation, or due to chronic joint degeneration in elderly patients. In 1941, Badgley ${ }^{8}$ affirmed that $\sim 80 \%$ of sciatica and low back pain cases occur because of referred pain related to facet origin instead of direct nerve root compression.

In general, low back pain is among the most frequent pathologies worldwide, with estimated incidence ranging from $11 \%$ to $84 \%$, and represents the second highest cause of demand for medical treatment in primary care. Among the adult population, $80 \%$ of the individuals present at least one episode of low back pain during their lives. ${ }^{6,9,10}$

This disease affects the active population all over the world, causing economic loss due to work absenteeism, as well as high cost of inpatient and medical-hospital care. Also, $11 \%$ to $76 \%$ of the patients who have intense pain report that it significantly interferes with their normal daily activities. ${ }^{4,10}$

In a study published in 2007, the authors affirmed that, among the multiple causes of low back pain, facet syndrome is responsible for $15-40 \%$ of the cases. ${ }^{11}$ The authors of another study, published in the same year, found that the prevalence of this syndrome ranged from $15 \%$ to $52 \%$ in the population presenting with chronic low back pain. ${ }^{12}$ However, it is worth mentioning that in only $15 \%$ of the chronic low back pain cases it is possible to identify the precise etiology of the pain. ${ }^{9}$ This is due to the fact that low back pain presents multifactorial origin and encompasses numerous determinant factors, such as: socioeconomic and demographic characteristics, urban sedentary lifestyle, obesity, nicotine addiction, inappropriate postural habits adopted during work, and psychosocial causes. ${ }^{4}$
This study aimed to present a systematic literature review about facet syndrome as well as a meta-analysis of radiofrequency denervation outcomes in patients presenting with this syndrome.

\section{Methods}

To emphasize medicine based on evidence, the method adopted to perform this study consists of a systematic literature review on facet syndrome, including an analysis of studies performed using several methods and a metaanalysis of radiofrequency denervation outcomes in patients presenting with this syndrome, selecting only case-control studies.

The active search for data was accomplished from January to December 2013, in books and journals at the Central Library of the Pontifícia Universidade Católica de Goiás (PUC-GO), as well as in articles published from 1999 to 2013 available in Bireme, Scielo, PubMed, and MEDLINE databases. We used the following descriptors in English, and the correspondent ones in Portuguese and Spanish, to select the articles: chronic low back pain, facet joint, zygapophysial joint, rhizotomy, facet syndrome, and radiofrequency facet denervation. As a result, we found 3,443 articles related to these descriptors.

All the articles identified using the aforementioned strategy were independently assessed by two of the authors, according to the following inclusion criteria: (1) patients presenting with chronic low back pain ( $\geq 3$ months) that used local anesthetic facet joint block for the diagnosis of facet syndrome; (2) articles published from 1999 on; (3) articles evidencing the effects of radiofrequency denervation in the treatment of patients presenting with chronic low back pain; (4) articles displaying the chosen descriptors in English, Portuguese, or Spanish. Studies which assessed other etiological factors of chronic low back pain (different from the presence of alterations in the facet joint), or used another topographic region of facet alterations (different from cervical and thoracic), or presented repeated information or data available in other articles were excluded.

After applying the inclusion and exclusion criteria, 52 articles were selected for the present systematic literature 
review. Among them, we selected a total of eight case-control studies to perform the meta-analysis.

To evaluate the heterogeneity among the grouped studies and carry out an effective combination of their results, we employed the chi-square $\left(x^{2}\right)$ test for heterogeneity. This calculation was necessary for the comparison of different Odds Ratios (ORs), at a 95\% confidence interval (95\% CI), determined in the respective studies.

Global association tests were then applied to assess the significance of the correlation between radiofrequency facet denervation in patients presenting with chronic low back pain and facet syndrome for all the studies combined. To estimate the effect of the proposed correlation, we combined the values of each study with the Mantel-Haensze test, which has fixed effects, using the BioEstat 5.0 software (Instituto de Desenvolvimento Sustentável Mamirauá, Tefé, AM, Brazil). To carry out this test, we calculated the OR and 95\% CI for each study individually and combined, generating the estimate of the grouped effect. This allowed us to generate a forest plot graph, which summarizes the details of the effect and contribution of each study.

\section{Literature Review}

As already mentioned, facet syndrome is a chronic lower back pain with multifactorial etiology, which occurs when the facet joint wears out or becomes degenerated, and is originated in any structure of these joints. ${ }^{1-6}$

\section{Anatomy and Physiology of Facet Joints}

To better understand this syndrome it is extremely important to acquire broad knowledge on the anatomy of the structures of the facet joint previously described. The facet joints, also known as zygapophysial joints, are located posterior-laterally to the vertebral column and connect the superior and inferior joint processes of adjacent vertebrae. Since they are true synovial joints, each facet joint has an articular space capable of accommodating some milliliters of synovial fluid, a synovial membrane, the hyaline cartilage, and a fibrous capsule. ${ }^{2,13}$

The facet joints are innervated by articular branches that originate in the medial branches, which in turn originate in the posterior branches of the spinal nerves. Since these nerves follow a posterior-inferior path, they are situated in grooves in the posterior surfaces of the medial parts of the transverse processes. Each articular branch feeds two adjacent joints and, therefore, each facet joint is fed by two small branches of the larger spinal nerves. ${ }^{13}$

In young individuals, the facet joints are very strong; however, with the aging process they become weaker and more biplanar, changing from a coronal to a sagittal plane, and the sensibilization of this structure generates pain. ${ }^{2} \mathrm{An}$ anatomy and epidemiological study of facet arthrosis in the lumbar column of cadavers demonstrated that this finding was present in $100 \%$ of the specimens over 60 years old, the most common level of arthritic alterations was in L4-L5, and males presented higher prevalence and degree of facet arthrosis than females. $^{14}$
Disc degeneration is determined by inappropriate postures, repetitive movements, muscle tension, and stress, which provoke traumas of low amplitude that accumulate during lifetime. ${ }^{1,2,4,6}$ This causes chronic inflammation of facet synovial joints, synovial fluid extravasation, articular capsule stretching, and pain due to articular hypertrophy and nerve compression.

\section{Diagnosis}

Several authors have been trying to gather a group of pathognomonic signs or at least of symptoms suggestive of lumbar facet syndrome. However, the clinical aspects of facet joint pain are generally nonspecific. ${ }^{2,15-17}$ Patients frequently report a sensation of deep pain in the lumbar paravertebral region and, several times, they also have referred pain in the gluteal region, posterior part of the thigh, and knee. The pain is often reproduced with the lateral extension and flexion of the lumbar spine to the symptomatic side, whereas the straight elevation of the leg is not painful. ${ }^{15}$

Regarding complementary exams, some studies suggest that magnetic resonance imaging has higher sensitivity than computed tomography to detect degenerative alterations in the facet joint. Nevertheless, none of these techniques identifies precisely the etiology of pain, since they merely indicate its location. ${ }^{1,2,18}$ Authors have also proposed the single photon emission computed tomography (SPECT) for the diagnosis of facet syndrome. ${ }^{19}$ Nonetheless, the evidence found in the literature suggest that the diagnosis of facet joint pain should not rely only on routine imaging. $2,15,19$

Due to nonspecific symptoms and lack of imaging confirmation for facet syndrome, researchers generally diagnose it using facet joint anesthetic block before performing facet denervation by radiofrequency. ${ }^{1,4-6,10,12,15,20,21}$ Facet joint blocks consist of intra-articular injections of a small amount of local anesthetic in the medial branch, which originates the joint branches that innervate the facet joints. The block can be simple or double, and the number of false-positive tests decreases when a double block is performed. ${ }^{2,5,10,17,22,23}$ In a study designed to evaluate the utility of Revel's criteria as a screening tool to select chronic low back pain patients for controlled diagnostic zygapophysial joint blocks, the authors concluded that they are unsuitable for this purpose. ${ }^{16}$

It is common to measure the low back pain before and after performing the diagnostic block using the Visual Analogic Scale (VAS). This scale presents good correlation and sensitivity for the diagnosis of facet syndrome when a relief of at least $50 \%$ of pain intensity is achieved comparing the values pre- and post-block. ${ }^{24}$

In spite of being frequently used in clinical practice, several factors may compromise the results of diagnostic block. For instance, small amounts of local anesthetic injected in the tissues can also block nerve branches, which would block the structures that these branches innervate (such as paravertebral muscles, fascia, ligaments, sacroiliac joint, and skin), therefore, relieving low back pain of any origin.

Nevertheless, a recent study demonstrated that patients presenting with chronic low back pain present only one 
probable type of etiology for the origin of pain. According to the authors, a combination of discogenic-facet, or facetarticular, or sacroiliac pain has been reported by less than $5 \%$ of the patients presenting with chronic low back pain. Thus, facet syndrome block would be an efficient method for the diagnosis of chronic low back pain. ${ }^{19}$ Other studies corroborate the importance and effectiveness of controlled medial branch block for the diagnosis of facet syndrome. However, a three-month follow-up is required to avoid a high number of false positive results. ${ }^{25}$ In conclusion, patients who experience significant pain relief following diagnostic block with local anesthetics are good candidates for radiofrequency medial branch neurotomy. ${ }^{5,22}$

\section{Treatment}

Several therapeutic techniques with controversial results have already been described and used for the treatment of low back pain of facet joint origin, such as: physical therapy, relative rest, acupuncture, analgesics, chiropractic manipulation, ${ }^{26}$ intra-articular steroid injections in the lumbar facet joints, nerve blocks, and radiofrequency denervation, ${ }^{27}$ the latter being the major focus of the present work.

\section{Radiofrequency Denervation}

In 1971, Rees published a specific method for facet denervation and was the first author to describe percutaneous denervation as an efficient treatment for low back pains. ${ }^{2,15}$ The principle of neurotomy is based on the fact that when a nerve that feeds a painful structure is damaged, the pain is relieved, therefore allowing that structure to perform its function again. ${ }^{22}$

A technique performed currently, attributed to Shealy, ${ }^{28}$ involves the use of radiofrequency energy channeled through a small-caliber needle to create a controlled and irreversible ablation that interrupts the innervations of the facet joint. As described before, the joint branches follow a posterior-inferior path and are situated in grooves in the posterior surfaces of the medial parts of the transverse processes. This means that the electrode should be placed in such a way that it passes over the dorsal surface of the transverse process, passing snugly along the groove, so that medially it abuts against the root of the superior articular process, and ventrally it glances along the dorsal surface of the transverse process. $^{18}$

Most authors concluded that radiofrequency electrodes produce, at their tips, little distal lesion and, therefore, may fail nerve ablation when used this way. Consequently, the electrodes should be preferentially placed in a transversal position to produce better results. ${ }^{2,12}$ To perform the procedure using the conventional technique, it is necessary to place the patient lying in the prone position. The lumbar column is visualized using X-ray and adjusted according to the need to obtain the alignment of the vertebral endplates and centralization of the spinous process. ${ }^{5}$

The skin and subcutaneous tissue should be anesthetized before the insertion of the cannula. The impedance should be verified at 300-700 ohms to confirm proper electrode placement and integrity of the radiofrequency system. ${ }^{2,12}$ The ablation in the medial branch lasts between 60 to 80 seconds at temperatures ranging from 70 to $90^{\circ} \mathrm{C}$ and should be performed for each nerve previously selected. ${ }^{2,5,12}$ Lowvoltage sensory stimulation is performed (up to $1 \mathrm{~V}$ at $50 \mathrm{~Hz}$ with 1-millisecond pulse duration) to ensure that stimulation reproduces concordant pain and only symptomatic levels are denervated. Motor stimulation is performed (up to $3 \mathrm{~V}$ at $2 \mathrm{~Hz}$ with 1-millisecond pulse duration) to verify proper electrode placement and exclude placement near the ventral ramus. Contractions of the multifidus muscle should be observed between 0.3 and $0.5 \mathrm{~V}$ when the electrode is properly placed. If the patient experiences sensory or motor manifestations in the inferior limb, the cannula should be repositioned. ${ }^{2,12}$

Serious complications and collateral effects are extremely rare after facet interventions. Dysesthesia has been observed after radiofrequency denervation, but this condition is transient and self-limited. ${ }^{2,15,17,21}$ The most common complication after this surgical procedure is neuritis, with an incidence lower than $5 \% .^{2}$ Infections have been reported after intra-articular lumbar facet joint injections, including septic arthritis, epidural abscess, and meningitis, although at a low global rate of $3.5 \%{ }^{12}$

\section{Results}

-Table 1 shows the characteristics of the eight studies selected for the present meta-analysis, encompassing a total of 440 patients. Among these patients, 220 underwent treatment with radiofrequency facet denervation and 220 received a placebo treatment. The mean age was 47 to 58 years in the treatment group (60.9\% females) and 38 to 57 years in the control group (58.18\% females). It is interesting to observe that only in the study conducted by Birkenmaier et $\mathrm{al}^{29}$ was the gender of patients under treatment and that of the control groups not mentioned.

All the studies employed the VAS pre- and post-block to evaluate pain relief and generate statistical data to corroborate the benefits of radiofrequency facet denervation in the treatment of facet syndrome. For each article, we grouped data showing the efficacy of facet denervation to relieve chronic low back pain, employing VAS pre- and post-block. This way, for each study the OR and its variations were calculated within the 95\% CI (-Table 1). To assess the heterogeneity among the grouped studies, we employed the chi-square test for heterogeneity, resulting in $X^{2}=3.436$ and $p=0.842$.

Based on the forest plot graph (-Fig. 1), all the studies were statistically relevant when grouped, determining an effect in favor of the use of facet denervation as a technique capable of relieving chronic low back pain in pre-determined periods of follow-up ( $\mathrm{OR}=1.251$; 95\% CI: 1.028-1.524). However, none of the studies presented statistical relevance in the individual evaluation because the $95 \% \mathrm{CI}$ was lower than 1, even having evidence of the risk in favor of the use of facet denervation for relieving chronic low back pain (OR $>1)$.

In - Fig. 1 the central squares represent OR or crossed-risk ratio and proposes the sample group of each study. The studies performed by Tejeda-Barreras et al. ${ }^{31}$ and Lakemeier 
Table 1 Characteristics of treatment and control groups in eight studies about radiofrequency facet denervation selected for the present meta-analysis

\begin{tabular}{|c|c|c|c|c|c|c|c|c|c|c|c|c|c|c|c|}
\hline \multirow[t]{2}{*}{ Reference } & \multirow[t]{2}{*}{ Year } & \multirow[t]{2}{*}{$\mathrm{T}$} & \multicolumn{6}{|c|}{ Treatment group } & \multicolumn{6}{|c|}{ Control group } & \multirow[t]{2}{*}{$\mathrm{Nt}$} \\
\hline & & & A & $M$ & $F$ & $\mathrm{~N}$ & VASb & VASa & A & $M$ & $F$ & $\mathrm{~N}$ & VASb & VASa & \\
\hline van Kleef et al $\left.\right|^{33}$ & 1999 & 2 & 47 & 5 & 10 & 15 & 5.2 & 2.83 & 41 & 6 & 10 & 16 & 5.2 & 4.77 & 31 \\
\hline Leclaire et $\mathrm{al}^{22}$ & 2001 & 1 & 47 & 12 & 24 & 36 & 5.18 & 4.82 & 46 & 13 & 21 & 34 & 5.15 & 5.21 & 70 \\
\hline van Wijk et al ${ }^{20}$ & 2005 & 3 & 47 & 10 & 30 & 40 & 5.8 & 3.7 & 48 & 13 & 28 & 41 & 6.1 & 4.5 & 81 \\
\hline Birkenmaier et al ${ }^{30}$ & 2007 & 6 & 56 & NM & NM & 13 & 7.4 & 2.7 & 55 & $\mathrm{NM}$ & $\mathrm{NM}$ & 13 & 8.2 & 4 & 26 \\
\hline Nath et al $^{5}$ & 2008 & 6 & 56 & 6 & 14 & 20 & 5.98 & 3.88 & 53 & 9 & 11 & 20 & 4.38 & 3.68 & 40 \\
\hline Tejeda-Barreras et al ${ }^{32}$ & 2010 & 6 & 50 & 8 & 12 & 20 & 8.6 & 4.5 & 43 & 7 & 13 & 20 & 8.7 & 4.6 & 40 \\
\hline Civelek et $\mathrm{al}^{30}$ & 2012 & 6 & 52 & 15 & 35 & 50 & 8.2 & 2.5 & 57 & 15 & 35 & 50 & 8.5 & 4.4 & 100 \\
\hline Lakemeier et al $^{27}$ & 2013 & 6 & 58 & 17 & 9 & 26 & 6.6 & 4.7 & 56 & 16 & 10 & 26 & 7 & 5.4 & 52 \\
\hline
\end{tabular}

Abbreviations: A, age (years); F, female; M, male; N, number of participants; NM, not mentioned; $\mathrm{Nt}$, total number of participants; T, follow-up period (months); VASa, pain assessment after radiofrequency facet denervation using the Visual Analogical Scale; VASb, pain assessment before radiofrequency facet denervation using the Visual Analogical Scale.

et al. $^{27}$ presented higher relevance, since they evidenced more precise results and a greater contribution for the present meta-analysis.

\section{Discussion}

As already mentioned, the treatment of facet joint pain consists of a multimodal approach and the best results have been attributed to radiofrequency denervation. Nonetheless, the studies on this subject are scarce and have presented conflicting conclusions.
In a case-control study performed in 2001, the authors did not find significant difference in relief of low back pain due to facet syndrome in the long run between the group treated with radiofrequency denervation and the control group, which was given a placebo treatment. ${ }^{22}$ In a previous study, performed in 1999, the same method was used and the authors concluded that radiofrequency denervation is efficient in the treatment of facet syndrome in the short and long run. $^{32}$

Based on these discrepancies, the need and importance of the present study are enhanced, since the meta-analysis is a

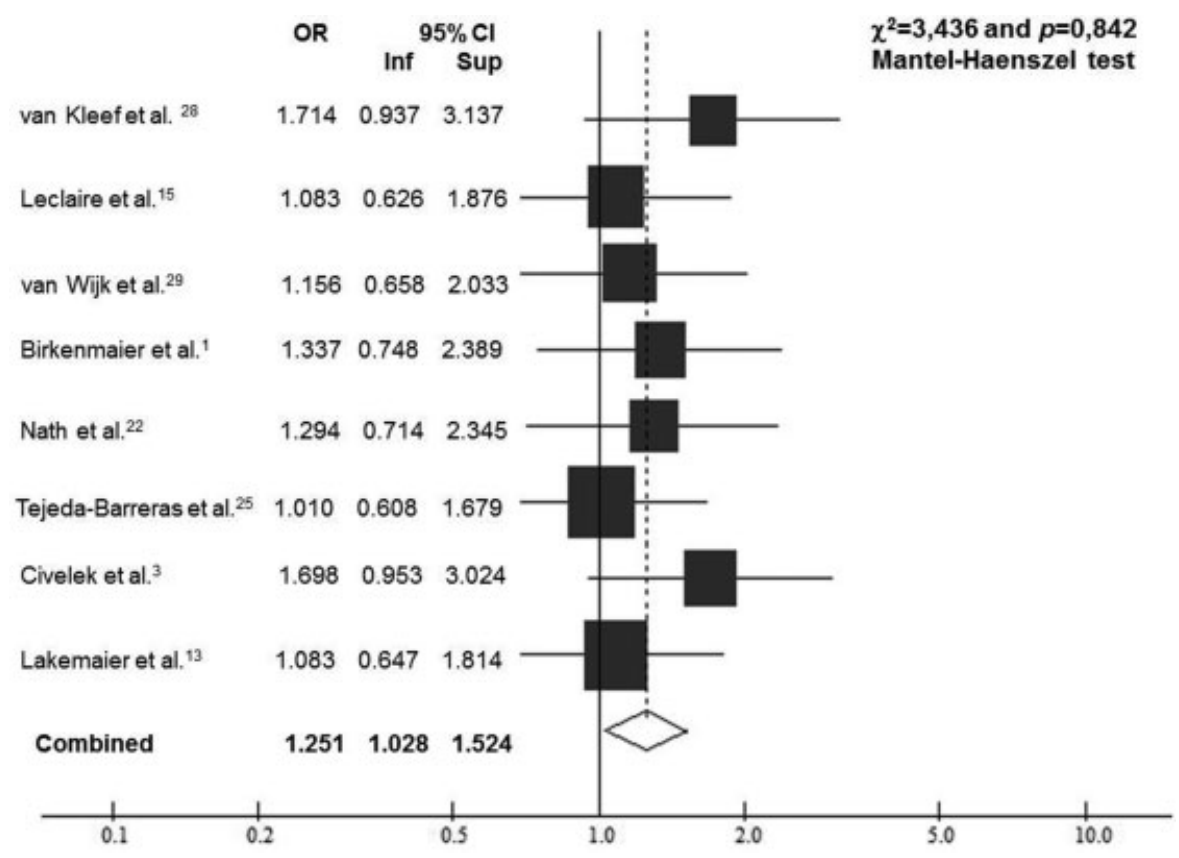

Fig. 1 Forest plot showing the treatment of facet syndrome using radiofrequency denervation. 
method capable of analyzing several other studies on the same theme and allowing a synthesis of their results, leading to grouped and more precise conclusions. ${ }^{33}$ Furthermore, to the best of our knowledge, the results presented herein are unique, because in the period under study, from 1999 to 2013, we found no similar meta-analyses in the databases consulted.

Although the eight case-control studies selected did not present significant relevance when analyzed individually (-Fig. 1), when they were grouped, it was possible to demonstrate that radiofrequency facet denervation is an effective technique to treat facet syndrome in patients previously selected. This statistical difference occurred because, when grouping all the case-control studies selected, the sample encompassed 440 patients.

Moreover, the quality of the articles selected was homogenous according to the result of the chi-square test for heterogeneity, with $p=0.842$. Thus, we observed no significant differences in the characteristics of the treatment and control groups (-Table 1). Most patients were between the fifth and sixth decades of life and a higher incidence of facet syndrome was registered for females, which disagrees with the findings of a study performed in 2007, mentioned in the literature review presented herein. ${ }^{14}$

Taking into consideration the radiofrequency technique, which is the most important feature of the articles analyzed, the fact that in seven studies the continuous technique was employed and in only one of them pulsed radiofrequency was used did not impair the results we obtained. Both techniques are similar in terms of efficacy when the follow-up is inferior to six months, ${ }^{2,12}$ exactly the same followup period established in this study.

\section{Conclusions}

Based on the results of this study, it is possible to conclude that the treatment of low back pain of facet joint origin using radiofrequency is effective for relieving the pain, provided that strict protocols of patient selection and a very refined technique are employed. The precise diagnosis of facet syndrome in patients presenting with chronic low back pain is the key element to obtain the benefits of radiofrequency denervation. Therefore, studies approaching more precise techniques for the diagnosis of this condition are of paramount importance to provide doctors with better tools to correctly deal with facet syndrome.

The results of the systematic literature review and metaanalysis herein presented may be used as the basis for the creation of diagnosis and management protocols for facet syndrome, and can also stimulate other researchers to conduct further studies on this subject.

\section{Conflicts of Interest}

The authors declare no conflict of interest.

\section{References}

1 Cohen SP, Raja SN. Pathogenesis, diagnosis, and treatment of lumbar zygapophysial (facet) joint pain. Anesthesiology 2007; 106(3):591-614

2 Kornick C, Kramarich SS, Lamer TJ, Todd Sitzman B. Complications of lumbar facet radiofrequency denervation. Spine 2004;29(12): 1352-1354

3 Martínez-Suárez JE, Camblor L, Salva S, De Jongh WA. Termocoagulación facetaria lumbar. Experiencia en 252 pacientes. Rev Soc Esp Dolor 2005;12(7):425-428

4 Matos MG, Hennington EA, Hoefel AL, Dias-da-Costa JS. Dor lombar em usuários de um plano de saúde: prevalência e fatores associados. Cad Saude Publica 2008;24(9):2115-2122

5 Nath S, Nath CA, Pettersson K. Percutaneous lumbar zygapophysial (Facet) joint neurotomy using radiofrequency current, in the management of chronic low back pain: a randomized doubleblind trial. Spine 2008;33(12):1291-1297, discussion 1298

6 Insausti Valdivia J. Lumbalgia inespecífica: en busca del origen del dolor. Reumatol Clin 2009;5(Suppl 2):19-26

7 Ghormley RK. Low back pain with special reference to the articular facets, with presentation of an operative procedure. JAMA 1933;101(23):1773-1777

8 Badgley CE. The articular facets in relation to low-back pain and sciatic radiation. J Bone Joint Surg Am 1941;23:481-496

9 Celik B, Er U, Simsek S, Altug T, Bavbek M. Effectiveness of lumbar zygapophysial joint blockage for low back pain. Turk Neurosurg 2011;21(4):467-470

10 Durán BB. Lumbalgia. An Radiol Mex 2005;2:89-97

11 Cohen SP, Hurley RW, Christo PJ, Winkley J, Mohiuddin MM, Stojanovic MP. Clinical predictors of success and failure for lumbar facet radiofrequency denervation. Clin J Pain 2007;23(1):45-52

12 Tekin I, Mirzai H, Ok G, Erbuyun K, Vatansever D. A comparison of conventional and pulsed radiofrequency denervation in the treatment of chronic facet joint pain. Clin J Pain 2007;23(6): 524-529

13 Moore KL, Dalley AF, Agur AMR. Clinically oriented anatomy. 6th ed. Philadelphia: Lippincott Williams Wilkins; 2008

14 Eubanks JD, Lee MJ, Cassinelli E, Ahn NU. Prevalence of lumbar facet arthrosis and its relationship to age, sex, and race: an anatomic study of cadaveric specimens. Spine 2007;32(19): 2058-2062

15 Whitworth LA, Feler CA. Application of spinal ablative techniques for the treatment of benign chronic painful conditions: history, methods, and outcomes. Spine 2002;27(22):2607-2612, discussion 2613

16 Laslett M, Öberg B, Aprill CN, McDonald B. Zygapophysial joint blocks in chronic low back pain: a test of Revel's model as a screening test. BMC Musculoskelet Disord 2004;5:43

17 Lee CJ, Kim YC, Shin JH, et al. Intravascular injection in lumbar medial branch block: a prospective evaluation of 1433 injections. Anesth Analg 2008;106(4):1274-1278

18 Dreyfuss P, Halbrook B, Pauza K, Joshi A, McLarty J, Bogduk N. Efficacy and validity of radiofrequency neurotomy for chronic lumbar zygapophysial joint pain. Spine 2000;25(10):1270-1277

19 Varlotta GP, Lefkowitz TR, Schweitzer M, et al. The lumbar facet joint: a review of current knowledge: Part II: diagnosis and management. Skeletal Radiol 2011;40(2):149-157

20 van Wijk RMAW, Geurts JWM, Wynne HJ, et al. Radiofrequency denervation of lumbar facet joints in the treatment of chronic low back pain: a randomized, double-blind, sham lesion-controlled trial. Clin J Pain 2005;21(4):335-344

21 Verrills P, Mitchell B, Vivian D, Nowesenitz G, Lovell B, Sinclair C. The incidence of intravascular penetration in medial branch blocks: cervical, thoracic, and lumbar spines. Spine 2008;33(6): E174-E177

22 Leclaire R, Fortin L, Lambert R, Bergeron YM, Rossignol M. Radiofrequency facet joint denervation in the treatment of low back 
pain: a placebo-controlled clinical trial to assess efficacy. Spine 2001;26(13):1411-1416, discussion 1417

23 Mikeladze G, Espinal R, Finnegan R, Routon J, Martin D. Pulsed radiofrequency application in treatment of chronic zygapophyseal joint pain. Spine J 2003;3(5):360-362

24 Cohen SP, Stojanovic MP, Crooks M, et al. Lumbar zygapophysial (facet) joint radiofrequency denervation success as a function of pain relief during diagnostic medial branch blocks: a multicenter analysis. Spine J 2008;8(3):498-504

25 Rocha ID, Cristante AF, Marcon RM, Oliveira RP, Letaif OB, Barros Filho TEP. Controlled medial branch anesthetic block in the diagnosis of chronic lumbar facet joint pain: the value of a three-month follow-up. Clinics (Sao Paulo) 2014;69(8):529-534

26 Grabow TS, Block BM. Facet joint injection. In: Mauro MA, Murphy KPJ, Thomson KR, Venbrux AC, Morgan RA editors. Image-guided interventions. Philadelphia: Elsevier Saunders; 2008:1234-1242

27 Lakemeier S, Lind M, Schultz W, et al. A comparison of intraarticular lumbar facet joint steroid injections and lumbar facet joint radiofrequency denervation in the treatment of low back pain: a randomized, controlled, double-blind trial. Anesth Analg 2013; 117(1):228-235

28 Shealy CN. Facet denervation in the management of back and sciatic pain. Clin Orthop Relat Res 1976;(115):157-164

29 Birkenmaier C, Veihelmann A, Trouillier HH, Hausdorf J, von Schulze Pellengahr C. Medial branch blocks versus pericapsular blocks in selecting patients for percutaneous cryodenervation of lumbar facet joints. Reg Anesth Pain Med 2007;32(1):27-33

30 Civelek E, Cansever T, Kabatas S, et al. Comparison of effectiveness of facet joint injection and radiofrequency denervation in chronic low back pain. Turk Neurosurg 2012;22(2):200-206

31 Tejeda-Barreras M, Rodríguez-Celaya C, Santillana-Macedo MA. Tratamiento de dolor lumbar crónico mediante radiofrecuencia pulsada y aplicación de esteroides em forma epidural. Estudio Comparativo Coluna 2010;9(1):24-29

32 van Kleef M, Barendse GAM, Kessels A, Voets HM, Weber WEJ, de Lange S. Randomized trial of radiofrequency lumbar facet denervation for chronic low back pain. Spine 1999;24(18):1937-1942

33 Luiz AJB. Meta-análise: definição, aplicações e sinergia com dados espaciais. Cad Cien Tecnol 2002;19(3):407-428 